\title{
Sturge-Weber syndrome: CT and MRI illustrations
}

\author{
Siddarth Ragupathi, ${ }^{1}$ Ajit Kumar Reddy ${ }^{2}$ Annitha Elavarasi Jayamohan, ${ }^{2}$ \\ Prakash Manikka Lakshmanan ${ }^{3}$
}

Department of Radiology, Mahatma Gandhi Medical College and Research Institute, Kumbakonam, Tamil Nadu, India

${ }^{2}$ Mahatma Gandhi Medical College \& Research Institute, Pondicherry, India ${ }^{3}$ Department of Radiology, Mahatma Gandhi Medical College \& Research Institute, Pondicherry, India

\section{Correspondence to} Dr Ajit Kumar Reddy, drajitreddy@gmail.com

Accepted 21 October 2014

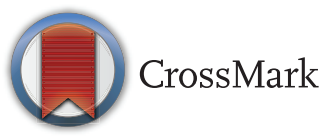

To cite: Ragupathi $\mathrm{S}$, Reddy AK, Jayamohan AE, et al. BMJ Case Rep Published online: [please include Day Month Year] doi:10.1136/bcr-2014205743

\section{DESCRIPTION}

A three-and-half-year-old child with developmental delay presented to the paediatric department with a 2-day history of high-grade fever with chills and rigours. There was associated weakness of the right upper and lower limbs with an episode of seizure that lasted for $10 \mathrm{~min}$. The child was known to have seizures from 8 months of age and was on anticonvulsant treatment, which was stopped 3 months earlier.

Clinical examination revealed macrocephaly, port-wine stains on the left half of the body and reduced tone in right upper and lower limbs. CT and MRI of the brain revealed subcortical calcifications depicting 'tram-track'-like appearance in the
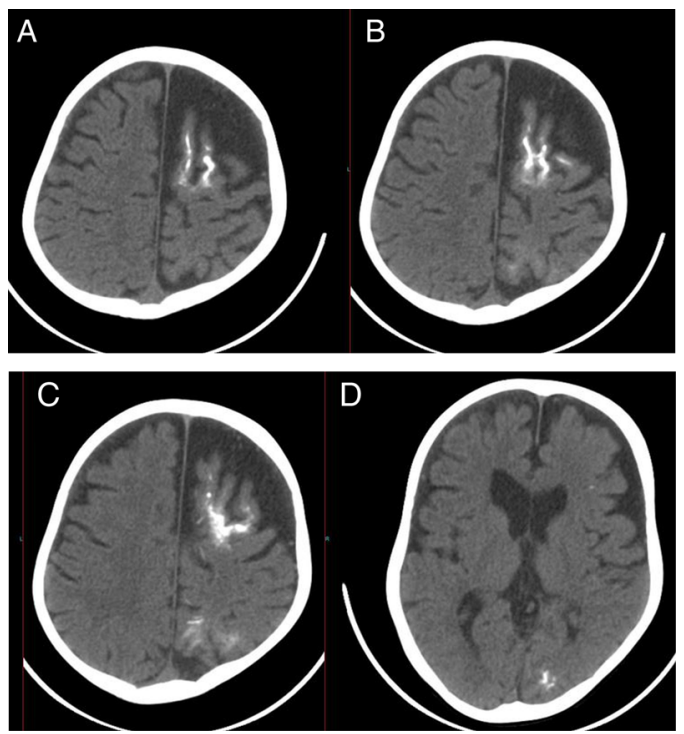

Figure 1 (A-D) CT axial image showing subcortical calcifications having a characteristic 'tram-track'-like appearance in the left frontal, parietal and occipital lobes with atrophy of cerebral cortex involving the left frontal lobe to a greater extent.

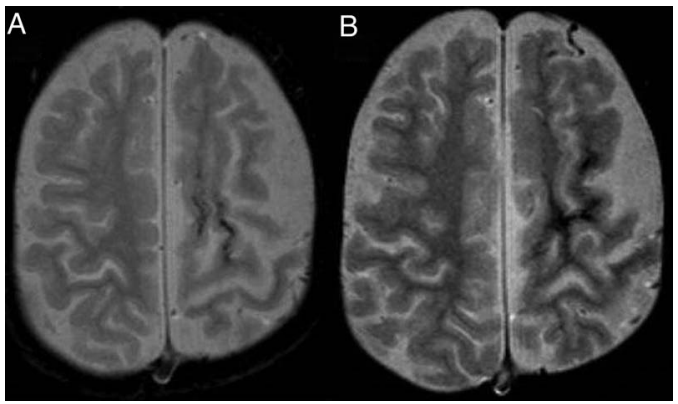

Figure 2 (A and B) MRI axial T2-weighted fast-field echo sequence showing subcortical calcifications with characteristic 'tram-track'-like appearance involving the left frontal and parietal regions.

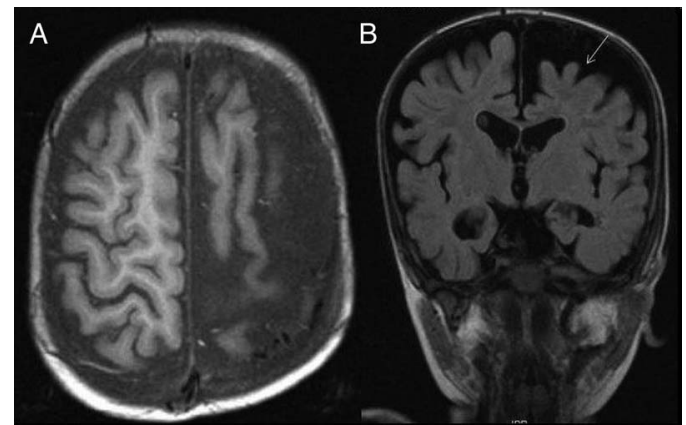

Figure 3 (A) MRI axial T1-weighted (T1W) spin-echo and (B) coronal T2W fluid-attenuated inversion recovery sequences showing atrophy of the cerebral cortex predominantly involving left frontal lobe.

left frontal, parietal and occipital lobes (figures 1 and 2). Hemiatrophy of the left frontal lobe (figure 3) with prominence of ventricles, basal cisterns, Sylvian fissures, left choroid plexus (figures 4 and 5) and hyperostosis of the calvarium was seen.

Sturge-Weber syndrome (SWS) is a rare neurocutaneous syndrome, usually sporadic in nature, which is a result of occlusion/stasis of the persistent fetal vasculature resulting in cortical anoxia. ${ }^{1}$ It is characterised by facial port-wine stain, leptomeningeal angiomatosis, congenital glaucoma, intractable epilepsy and progressive mental retardation. ${ }^{1}{ }^{2}$ These classical brain parenchymal changes can be demonstrated by imaging modalities such as CT

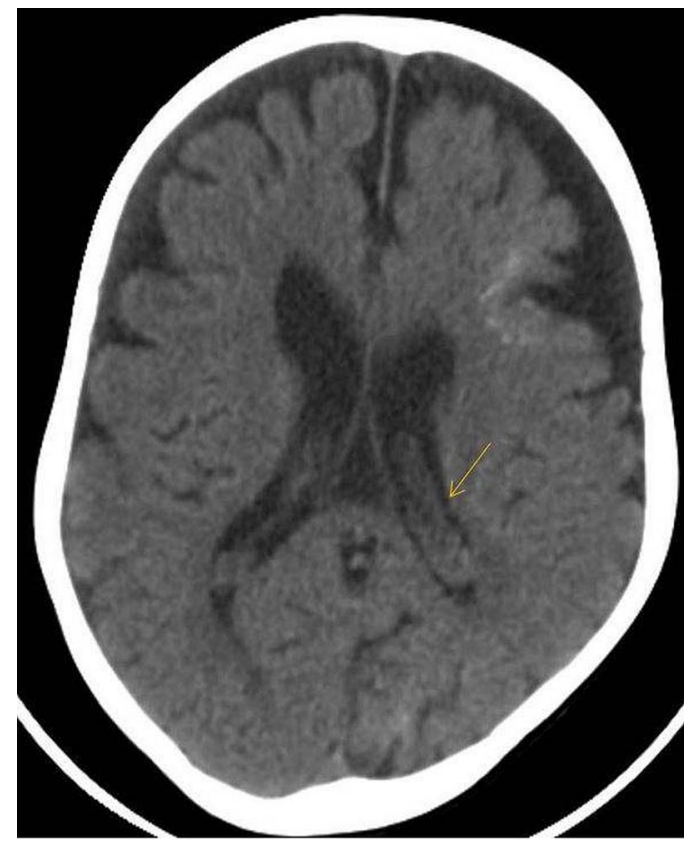

Figure $4 \mathrm{CT}$ axial image showing prominent left choroid plexus. 


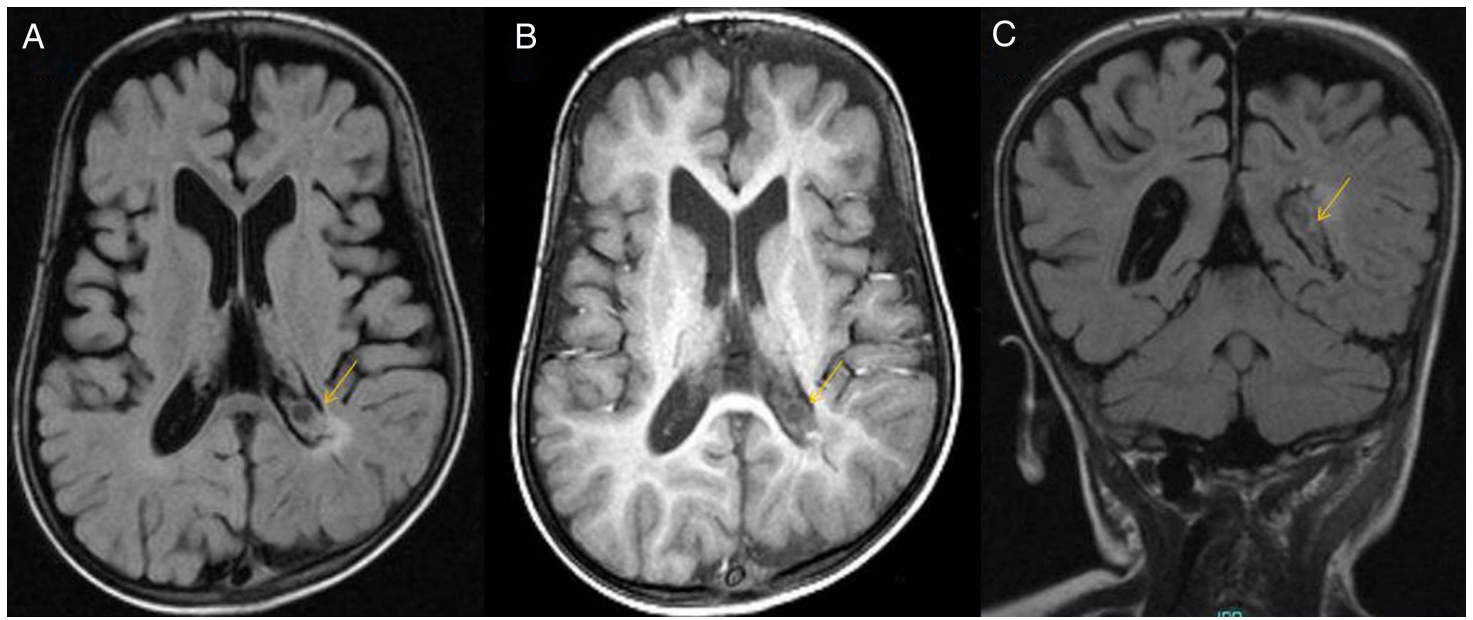

Figure 5 (A) MRI axial T1-weighted (T1W) spin-echo, (B) MRI axial T2W fluid-attenuated inversion recovery (FLAIR) and (C) coronal T2W FLAIR sequences showing prominent left choroid plexus.

and MRI. ${ }^{2}$ Since patients usually present with seizures, medical management is by the use of anticonvulsants with or without resection of affected lobes. Other vascular phakomatoses that form a part of the differential diagnosis include Blue rubber bleb nevus syndrome, Wyburn-Mason syndrome and Klippel-Trenaunay syndrome. Thus, early diagnosis and seizure management of SWS helps to improve quality of life and survival.

\section{Learning points}

- In a child with developmental delay presenting with seizures, macrocephaly, presence of port-wine stains on the body and imaging features of subcortical 'tram-track'-like pattern of calcifications, parenchymal volume loss, enlarged choroid plexus and calvarial hyperostosis are diagnostic of Sturge-Weber syndrome.

- Awareness of the condition may help in the improved quality of life and survival of these patients.

- Treatment includes seizure control, with surgical resection being restricted to refractory cases.
Contributors SR contributed to the idea, performed the literature analysis, manuscript writing and data collection. AKR and AEJ acquired informed consent, contributed towards data collection and imaging. PML made the final revision and gave approval of the manuscript.

\section{Competing interests None.}

Patient consent Obtained.

Provenance and peer review Not commissioned; externally peer reviewed.

\section{REFERENCES}

1 Rumboldt $\mathrm{Z}$, Castillo $\mathrm{M}$, Huang $\mathrm{B}$, et al, eds. Brain imaging with MRI and CT: an image pattern approach. Cambridge Medicine. 2013:428.

2 Thomas-Sohl K, Vaslow D, Maria B. Sturge-Weber syndrome: a review. Pediatr Neurol 2004;30:303-10.

Copyright 2014 BMJ Publishing Group. All rights reserved. For permission to reuse any of this content visit http://group.bmj.com/group/rights-licensing/permissions.

BMJ Case Report Fellows may re-use this article for personal use and teaching without any further permission.

Become a Fellow of BMJ Case Reports today and you can:

- Submit as many cases as you like

- Enjoy fast sympathetic peer review and rapid publication of accepted articles

- Access all the published articles

- Re-use any of the published material for personal use and teaching without further permission

For information on Institutional Fellowships contact consortiasales@bmjgroup.com

Visit casereports.bmj.com for more articles like this and to become a Fellow 